\title{
"NO HAY VIRTUD SIN EXPERIENCIA»: PRETENDIENTES INESPERADOS Y DAMAS AL ACECHO EN LA TRAGEDIA DEL SIGLO DE ORO "NÃO HÁ VIRTUDE SEM EXPERIÊNCIA": PRETENDENTES INESPERADOS E DAMAS À ESPREITA NA TRAGÉDIA DO SÉCULO DE OURO
}

María Rosa Álvarez Sellers

Recebido em 31 ago 2016. María Rosa Álvarez Sellers es doctora en Filología Aprovado em 01 out 2016. (Universitat de València); Licenciada en Filología Hispánica (Universitat de València) y Licenciada en Filología Portuguesa (Universidad de Salamanca). Profesora Titular (T.U.) de Filología Portuguesa (Dpto. Filología Española; Facultad de Filología, Traducción y Comunicación;) de la Universidad de València. Email: maria.r.alvarez@uv.es / CV completo en la página web del Proyecto Consolider.

Resumen: La figura del antagonista es clave en todo conflicto trágico, pues representa la oposición al orden establecido, el personaje que consigue desvelar el lado oscuro del héroe. Uno de los conflictos predilectos de la tragedia española del siglo XVII es aquel que enfrenta el amor al honor, el pasado al presente, el deber al deseo, y puede ser articulado por medio de una estructura tipificada: un matrimonio concertado cuya aparente armonía se verá irremisiblemente alterada por la llegada inesperada de un antiguo pretendiente de la esposa que reclama derechos sentimentales y cuya actuación comprometedora, 
unida a los errores de la protagonista, decidirá al marido - invocando el código del honor - a acabar con la vida de la dama. Pero no solo el pretendiente inesperado puede asumir el rol del antagonista en la tragedia de honra, también hay otro personaje cuya intervención, en principio secundaria, resultará a la postre decisiva: se trata de la que podríamos llamar "dama al acecho», aquella que no ha llegado a ser la preferida del protagonista pero que alienta la esperanza de recuperarlo a cualquier precio y sabe esperar su oportunidad. Analizaremos ambos personajes en obras representativas del género: $E l$ médico de su honra, El pintor de su deshonra, A secreto agravio, secreta venganza de Calderón de la Barca, El castigo sin venganza de Lope de Vega o La fuerza de la ley de Agustín Moreto.

Palabras clave: Tragedia; Siglo de Oro; Pretendiente; Dama; Calderón de la Barca; Lope de Vega; Agustín Moreto

Resumo: A figura do antagonista é chave em qualquer conflito trágico, dado que representa a oposição à ordem estabelecida, a personagem que consegue desvelar o lado obscuro do herói. Um dos conflitos prediletos da tragédia espanhola do século XVII é aquele em que se enfrentam o amor e o honor, o passado e o presente, o dever e o desejo, e pode ser articulado por meio de uma estrutura tipificada: um casamento concertado cuja aparente harmonia ver-se-á irremissivelmente alterada pela chegada inesperada de um antigo pretendente da esposa que reclama direitos sentimentais e cuja atuação comprometedora, unida aos erros da protagonista, levará o marido - invocando o código da honra - a decidir acabar com a vida da dama. Mas não só o pretendente inesperado pode assumir o papel de antagonista na tragédia de honra, também existe outra personagem cuja intervenção, no início secundário, será finalmente decisiva: trata-se da que poderíamos 
chamar "dama à espreita», aquela que não chegou a ser a preferida do protagonista, mas que alenta a esperança de recuperá-lo a qualquer preço e sabe esperar a sua oportunidade. Analisaremos ambas as personagens em obras representativas do género: $E$ I médico de su honra, El pintor de su deshonra, A secreto agravio, secreta venganza de Calderón de la Barca, El castigo sin venganza de Lope de Vega e La fuerza de la ley de Agustín Moreto.

Palavras-chave: Tragédia; Século de Ouro; Pretendente; Dama; Calderón de la Barca; Lope de Vega; Agustín Moreto

No culpéis la condición que en mí tan esquiva hallasteis; culpaos a vos, que llegasteis sin tiempo y sin ocasión. (I, vv. 697-700) Leonor en $A$ secreto agravio, secreta venganza, Calderón de la Barca

¡Dichoso el mal que tal bien ha causado! (III, vv. 2911-2912) Nise en La fuerza de la ley, Moreto

La tragedia se articula en torno a la dialéctica del conflicto, de aquello que los griegos llamaban agón y que traducía el enfrentamiento entre las fuerzas de la naturaleza - algo muere para que algo renazca -, cuyos efectos mágicos pasaron a representar situaciones cruciales de la vida humana que, sustituyendo a los rituales de fecundidad, se convertirían en temas de los géneros dramáticos. De esa lucha cíclica entre las potencias naturales para desplazarse alternativamente nacen lo trágico y lo cómico y la ambigüedad de ambos. El teatro griego los ha encuadrado en dos géneros, al asignarlos a dos tipos de ritos diferentes, y ha 
humanizado ambas circunstancias progresivamente. ${ }^{1}$ El teatro español del siglo XVII, liderado por Lope de Vega, se encargaría de demostrar que la mezcla de ambos elementos era necesaria, conveniente y adecuada para cimentar el edifico teatral sobre la verosimilitud y el éxito. ${ }^{2}$

Este elemento conflictivo es complejo, pues no afecta únicamente a personajes o intereses sino que también confronta el plano de lo humano con el de lo divino, entendiendo por "divino» no solo una conciencia religiosa determinada sino un orden superior impuesto al ser humano: una norma social, política, un absoluto moral... Un imponderable, en definitiva, que puede adoptar diversas formas pero que lleva siempre aparejado la elección y el sufrimiento, parámetros de la actuación del personaje trágico. Así pues, si en la tragedia griega esa instancia superior es encarnada por el fatum, en la tragedia áurea española podría definirse como un imperativo social al que debe supeditarse la conciencia y que el personaje noble sintetiza en la tan repetida fórmula «soy quien soy», que confirma su asunción del orden establecido. "Una ley, un amor, un albedrío, / una fe nos gobierna» (I, vv. 718-719) ${ }^{3}$ dice Aurora en El castigo sin venganza, definiendo con precisión los preceptos de la sociedad barroca que llevarán tanto a los maridos de las tragedias de honra amarrados a las leyes del honor como

1 «En estos rituales y en los géneros literarios que de ellos derivan - el Teatro y antes la Lírica - se ha expresado un primitivo pensamiento religioso. Pero luego, a partir de aquí, de los datos comprendidos en esas estructuras tipificadas que son los diversos rituales, los Misterios y, sobre todo, los géneros literarios, se han expandido el pensamiento religioso y el pensamiento general. Toda la especulación griega sobre el hombre proviene de aquí. Hasta que llegó el momento en que el marco del Teatro, como antes el de la Lírica, se hizo demasiado estrecho y la especulación continuó en la prosa de los filósofos». (RODRÍGUEZ ADRADOS, 1972, p.494)

2 Ver ÁLVAREZ SELLERS, 2012.

3 Lope de VEGA, El castigo sin venganza (1989). 
a los personajes rebeldes a las mismas a descubrir, enajenados o perplejos, la contradicción entre el deber y el deseo.

Uno de los conflictos favoritos de la tragedia española del siglo XVII es el que enfrenta el amor al honor, sostenido por una estructura tipificada: un matrimonio concertado cuya aparente armonía se verá alterada por el regreso inesperado de un antiguo pretendiente de la esposa, a quien esta creía muerto o desaparecido, que reclama derechos sentimentales y que se convertirá en antagonista de los cónyuges. Calderón escribe tres «tragedias de honra» con idéntico planteamiento y similar resolución: El médico de su honra $[\mathrm{MH}]$ (1635), El pintor de su deshonra [PD] (1645-1651) y A secreto agravio, secreta venganza [SASV] (1635). ${ }^{4}$

El pretendiente siempre llega por sorpresa e implica una alteración del orden establecido, pues permanece anclado en el pasado y se niega a aceptar la nueva situación de la que fue su enamorada, a la que incluso reprocha su olvido y su inconstancia. Altamente simbólica es la irrupción en escena de Don Enrique que, como Rosaura en la también calderoniana La vida es sueño, cae de su caballo, es decir, pierde la compostura y queda a merced de sus pasiones, nublada la luz de la razón por las pulsiones del instinto. ${ }^{5}$

4 Seguimos la cronología propuesta por RUIZ RAMÓN (1984, p.3). Para un análisis completo de las tres obras ver ÁLVAREZ SELLERS (1997, II, p.431-460), y de El castigo sin venganza (II, p.461-496).

5 Pero también será simbólica la del marido, pues cuando Mencía, angustiada por la insistencia de D. Enrique, que se ha colado en su jardín, llame a las fieras en su defensa, entrará D. Gutierre, que después se comportará como tal cuando crea en peligro su honor:

D. EnRIQUE. Ya llegué a hablarte, ya tuve ocasión, no he de perderla.

Dạ. Mencía. ¿Cómo esto los cielos sufren? Daré voces.

D. EnRIQUe. A ti misma te infamas. 
Inconsciente, es llevado a la quinta más cercana para ser asistido, y el azar quiere que despierte en brazos de la que fue su amada sin saber que ella ahora está casada:

Dạ. MenCÍA. [...]

que después sabrá de mí dónde está.

D. EnRIQUe. No lo deseo;

que si estoy vivo y te miro, ya mayor dicha no espero; ni mayor dicha tampoco, si te miro estando muerto; pues es fuerza que sea gloria donde vive ángel tan bello. $Y$ así no quiero saber qué acasos ni qué sucesos aquí mi vida guiaron, ni aquí la tuya trajeron; pues con saber que estoy donde estás tú, vivo contento; y así ni tú que decirme, ni yo que escucharte tengo.

Da. MEncíA. ¿Cómo no acuden a darme favor las fieras?

D. EnRIQUe. Porque de enojarme huyen. Dentro DON GUTIERRE.

D. Gutierre. Ten ese estribo, Coquín, y llama a esa puerta.

Dạ. Mencía. iCielos!

No mintieron mis recelos, llegó de mi vida el fin.

(MH, II, vv. 120-130)

Pedro CALDERÓN DE LA BARCA, El médico de su honra. El pintor de su deshonra (1970). 
Då. MencíA. ([Ap.] Presto de tantos favores

será desengaño el tiempo.)

(MH, I, vv. 183-200)

La situación se invierte en El pintor de su deshonra, donde Serafina despierta de un desmayo en brazos de Don Álvaro y se expresa con mayor claridad que Mencía para tratar de desengañarlo: "Viuda de ti me he casado» (I, v. 603), aunque el pretendiente, en ambos casos, oye pero no escucha e insiste en que ella lo abrace $(P D, I$, v. 621). Su actitud no cambia cuando se entera del nuevo estado de la dama, a la que pretende arrastrar consigo al tumulto de un pasado tan idílico como irrecuperable. Don Enrique no quiere escuchar las razones de Mencía, y Don Álvaro no da crédito a la mudanza de Serafina, que le pide que se marche:

D. ÁlvaRO. ¿Qué importará que blasonen

tus altiveces conmigo

de ser al viento y al agua

dura encina, escollo altivo,

si antes que rebelde tronco

fuiste girasol, que [al vivo]

rayo de amor abrasado,

enamoraste sus visos;

y edificio antes que escollo,

en cuyo apacible sitio

vive amor idolatrado

deste humano sacrificio?

Pues siendo así, ¿cómo puedo

acobardar mis designios,

si antes de haber sido encina 
armada de hojas, yo mismo

te conocí amante flor,

y antes también de haber sido

escollo armado de hiedra,

yo te conocí edificio?

(PD, II, vv. 221-268)

Serafina insiste en que "desa humilde fácil flor» y «dese amoroso edificio», el tiempo ha hecho «inmortal tronco» y «caduca ruina» (PD, II, vv. 269-288), pero ese momento de turbación que reconoce haber sentido al verlo será la rendija por la que la discordia se colará en su casa. También Mencía, a solas, admite haber dudado por un instante, «porque ya, con más acuerdo, / ni para sentir soy mía»:

Dạ. MencíA. [...]

«¡Aquí fué amor!» Mas ¿qué digo?

¿Qué es esto, cielos, qué es esto?

Yo soy quien soy. Vuelva el aire los repetidos acentos

que llevó; porque aun perdidos, no es bien que publiquen ellos

lo que yo debo callar;

porque ya, con más acuerdo,

ni para sentir soy mía;

y solamente me huelgo

de tener hoy que sentir,

por tener en mis deseos

que vencer; pues no hay virtud

sin experiencia. Perfecto 
está el oro en el crisol,

el imán en el acero,

el diamante en el diamante,

los metales en el fuego;

y así mi honor en sí mismo

se acrisola, cuando llego

a vencerme; pues no fuera

sin experiencias perfecto.

¡Piedad, divinos cielos!

¡Viva callando, pues callando muero!

(MH, I, vv. 131-153)

Pero comete el error de querer probarse a sí misma, pues «no hay virtud sin experiencia», aun sabiendo que "Pruebas de honor son peligrosas pruebas» (MH, III, v. 359). También Leonor elige la misma estrategia para hacer frente al pretendiente $y$, con él, a los embates del amor y el pasado, al tiempo que confiesa el temor a que su marido se entere, pues es consciente del riesgo que supone dar rienda suelta a los sentimientos:

Dạ. LEONOR. Amor, aunque en la ocasión esté, soy quien soy, vencerme puedo, no es liviandad, honra es la que a esta ocasión me puso; ella me ha de defender; que cuando ella me faltara, quedara yo, que también supiera darme la muerte, si no supiera vencer. 
Temblando estoy; cada paso

que siento, pienso que es

don Lope, y el viento mismo

se me figura que es él.

¿Si me escucha?, ¿si me oye?

¡Qué propio del miedo fué!

¡Que a tales riesgos se ponga

una principal mujer!

(SASV, II, vv. 546-563) ${ }^{6}$

Esa aparición inesperada del antagonista sirve para revelar dos hechos sorprendentes: que el pretendiente está vivo y que la dama se ha casado, informaciones de las que hasta entonces ambos carecían y que cambian por completo su perspectiva sentimental.

SERAFINA. [...]

don Álvaro, yo te amé

cuando imaginé ser tuya,

y pasando mi esperanza

desde perdida a difunta,

me casé: ahora soy quien soy.

Sobre esto tus quejas funda.

D. Álvaro. ¿Qué he de decir, si tú lloras?

SERAFINA. Engáñaste, si lo [juzgas].

Si lloran, mienten mis ojos.

[...]

las vierte el dolor, y al mismo

tiempo el honor me las hurta; [las lágrimas]

6 Pedro CALDERÓN DE LA BARCA, A secreto agravio, secreta venganza (1967). 
porque no pueda el dolor decir que del honor triunfa. (PD, l, vv. 1015-1048)

El matrimonio marca una frontera irremisible para ella, sorteable para él, pero los dos se empeñan en ponerse a prueba, ella para asegurar su resistencia y desmentir las acusaciones de inconstante y traidora - «aleve, falsa, perjura [...] ingrata» $(P D, \mathrm{I}, \mathrm{v}$. 958; v. 967), él para recuperar ese amor que sabe ignorado pero no perdido y así, conciertan un segundo encuentro:

Dạ. MEncíA. Dicen que el primer consejo

ha de ser de la mujer;

$[\ldots]$

cuanto a la dama, quizá

fuerza, y no mudanza fué:

oídla vos, que yo sé

que ella se disculpará.

(MH, l, vv. 405-424)

Leonor incluso comete la osadía de hablar en clave con D. Luis que aparece disfrazado de mercader de piedras preciosas, símbolo de la tentación- mientras le dirige un soneto a su marido del que el pretendiente deduce de inmediato una esperanza:

D. LUIS. Estas fueron sus razones, mira si hablaban conmigo:

$[\ldots]$

De vos, y no de mí, podéis quejaros, pues, aunque yo os estime como a esposo, es imposible, como sois, amaros.

Y puesto que así me ha dado 


$$
\begin{aligned}
& \text { disculpa de su mudanza, } \\
& \text { sea mi loca esperanza } \\
& \text { veneno y puñal dorado. } \\
& \text { (SASV, I, vv. 805-824) }
\end{aligned}
$$

Si Leonor, casada por poderes con el portugués Don Lope de Almeida, conoce a su marido en esa escena del reencuentro, Mencía y Serafina, por el contrario, ya se encuentran inmersas en la vida marital cuando este regresa, aunque la reacción inicial de las tres sea el rechazo. Sin embargo, esa debilidad que han mostrado jugará a favor del pretendiente, que encontrará en la criada una aliada insospechada que le permite entrar en el espacio vedado del hogar sin saberlo su señora, a la que la sirvienta cree estar ayudando. Pero cuando el pretendiente cruza ese umbral prohibido asistimos a la confrontación con el dueño del espacio conyugal, el marido y, contra lo que podría esperarse, los tres se sienten inferiores y dan muestras de una cobardía inusitada:

SiRENA. Esta es Leonor.

D. LuIS. ¡Ay de mí!

¡Cuántas veces esperé

esta ocasión! Ya quisiera

no haberla llegado a ver.

Da. LEONOR. Ya, señor don Luis, estáis

en mi casa, ya tenéis

la ocasión que habéis deseado.

(SASV, II, vv. 564-570)

FLORA. Señor don Álvaro, ya

que está seguro el camino,

seguidme. (Toma la otra luz.) 
D. ÁlVARO. Sí haré... con harto

temor.

FLORA. ¿¿De qué?

D. Álvaro. De haber visto

la verdad de cuán valiente

es en su casa un marido.

(PD, II, vv. 403-408)

D. ENRIQUE. ¿Qué haré en tanta confusión?

Dạ. MEncíA. Detrás de ese pabellón,

que en mi misma cuadra está,

os esconded.

D. ENRIQUE. No he sabido,

hasta la ocasión presente,

qué es temor. iOh qué valiente

debe de ser un marido! (Escóndese.)

(MH, II, 144-150)

Aunque el pretendiente se obstine en negarlo, el amor ya pertenece al pasado, circunstancia que, sin embargo, nunca ha escapado a la dama, consciente de los deberes que implica el matrimonio, ${ }^{7}$ y puesto que lo que pudo haber sido no fue, 7 Dạ. Mencía. Nací en Sevilla, y en ella

me vió Enrique, festejó

mis desdenes, celebró

mi nombre..., ifelice estrella!

Fuése, y mi padre atropella

la libertad que hubo en mí:

La mano a Gutierre di,

volvió Enrique, y en rigor,

tuve amor, $y$ tengo honor.

Esto es cuanto sé de mí.

(MH, I, vv. 566-574)

Serafina cuenta a Porcia su relación con Don Álvaro, interrumpida por los «conciertos tratados» entre su padre y Don Juan Roca para casarla, los cuales acabó de consumar la desaparición de Don Álvaro (PD, I, vv. 361-505). 
Calderón no puede estar de parte de quien trata de usurpar el honor ajeno, y se posiciona del lado del marido, que antes de descubrir la presencia del intruso se había confesado enamorado de su esposa, tal y como dice Don Gutierre a Mencía: «No dejo de ser amante / yo, mi bien, por ser marido» (MH, II, vv. 163164), haciendo notar la frontera existente entre ambos roles. Pero todo cambiará esa noche en que intuye que ella le miente, pues ante la inesperada - otra vez - e inoportuna visita nocturna del pretendiente, la dama se verá obligada a tomar una solución de urgencia para justificarse ante el marido que tendrá, sin que ella lo sepa, el efecto contrario al deseado, pues acabará comprometiéndola al encender la llama de la sospecha:

Då. Mencía. Porque

si yo no se lo dijera

y Gutierre lo sintiera,

la presunción era clara, pues no se desengañara de que yo cómplice era; y no fué dificultad en ocasión tan cruel, haciendo del ladrón fiel, engañar con la verdad. (MH, II, vv. 329-338)

D. LOPE. Leonor.

Dạ. LEONOR. Señor, ¿ipues qué intentas?

¿Ya no supiste la causa con que él entró? Ya supiste que yo no he sido culpada. 
D. LOPE. ¿Tal pudiera imaginar

quien te estima y quien te ama?

No, Leonor, sólo te digo

que ya aquí se declara

con nosotros...

Dạ. LEONOR. ¿YYa él no dijo

que aquí de Castilla estaba

ausente por una muerte?

Pues yo, señor, no sé nada.

D. LOPE. No te disculpes, Leonor.

Mira..., mira que me matas.

(SASV, II, vv. 882-895)

La dama no se atreve a hablarle al marido de ese regreso de improviso y pedirle que la libre del asedio del otro tanto por temor a que le atribuya responsabilidades como por sentirse culpable de haberse casado sin amor, aunque las circunstancias - Don Enrique es hermano del Rey ${ }^{8}$ y Don Álvaro y Don Luis han 8 Dạ. Mencía. [...]

Vuestra Alteza,

liberal de sus deseos, generoso de sus gustos, pródigo de sus afectos, puso los ojos en mí: es verdad, yo lo confieso. Bien sabe, de tantos años de experiencias, el respeto con que constante mi honor fué una montaña de hielo, conquistada de las flores, escuadrones que arma el tiempo.

Si me casé, ¿de qué engaño se queja, siendo sujeto imposible a sus pasiones, reservado a sus intentos, pues soy para dama más, lo que para esposa menos? (MH, I, vv. 289-306) 
sido dados por muertos - y la voluntad paterna decidieran por ella. La reaparición del pretendiente le despierta sentimientos latentes pero no olvidados, y el único consuelo que encuentra es probarse a sí misma que puede sepultarlos bajo la ley que rige no el corazón sino el matrimonio: el honor, opuestos - amor y honor - que, curiosamente, solo concilia el marido.

D. GUTIERRE. [...]

No te espantes que los ojos

también se quejen, señor; que dicen que amor y honor pueden, sin que a nadie asombre, permitir que llore un hombre;

y yo tengo honor y amor.

Honor, que siempre he guardado

como noble y bien nacido, y amor, que siempre he tenido como esposo enamorado: (MH, III, vv. 15-24)

La esposa queda a merced de su conciencia y del juicio ajeno, pues encarna los valores que constituyen el norte de ambos varones, el amor del pretendiente y el honor del esposo, y que para ella resultan incompatibles e incluso pertenecen a tiempos distintos. Y los dos la juzgarán culpable de traición: por olvido e inconstancia para el pretendiente, por desamor y deshonra para el marido. La sentencia será impuesta por el cónyuge tras pronunciar soliloquios en que lamentan que el honor no dependa de ellos ${ }^{9}$ y por eso mismo se vean en la obligación de extirpar de la 9 D. GUTIERRE. [...]

\footnotetext{
A peligro estáis, honor,
} 
sociedad el miembro enfermo, es decir, de acabar con la vida de una esposa que no supo estar a la altura de sus deberes, sin saber que, desde que el pretendiente introdujo la disyuntiva, Mencía y Serafina sacrificaron a ellos sus deseos. Solo Leonor es capaz de asumir el riesgo y decidirse por el pretendiente - «la osadía / ya sin freno me alienta; / que peligro pasado no escarmienta» (SASV, III, vv. 625-627)-, con el que concierta una última cita a la que Don Luis nunca llegará. Porque el pretendiente siembra

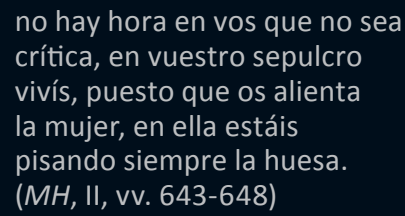

D. JUAN. [...]

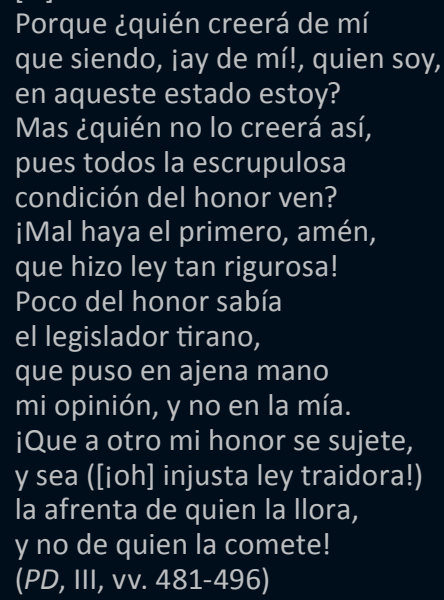

Igual sentir expresa el Duque de Ferrara en El castigo sin venganza, cuya deshonra, a diferencia de la de los maridos calderonianos, es un hecho consumado:

DUQUE. ¡Ay honor, fiero enemigo!

¿Quién fue el primero que dio

tu ley al mundo? iY que fuese

mujer quien en sí tuviese

tu valor, y el hombre no!

(III, vv. 2811-2815) 
la discordia pero también recogerá sus amargos frutos, y tanto Don Álvaro como Don Luis serán ejecutados por su antagonista, ese esposo arrastrado por una espiral de celos y temor a la deshonra ${ }^{10}$ que, en el caso de Don Gutierre y Don Juan Roca, les llevará al extremo de metaforizar la realidad hasta llegar a adoptar una identidad ficticia como «médico de su honra»o «pintor de su deshonra» que les otorga la potestad de acabar con la vida de su mujer y del supuesto amante. ${ }^{11}$ Solo sobrevive

10 Eugenio TRÍAS (1988, p.104-105) simboliza el sentir de los maridos mediante un monstruo de dos cabezas, los celos y el honor mancillado, que se escupen veneno y van minando la razón del sujeto:

"La inclinación natural, influjo de los elementos y los astros, se vuelve próxima al atroz determinismo en la pasión de amor. El determinismo acaba siendo ciego y feroz en la pasión de los celos. Estos son 'el mayor monstruo del mundo'. (...) Los celos son salvaje instinto que gobierna un mundo sin ley. El honor es bárbara ley que gobierna un mundo tiranizado por el instinto. Esta colisión somete a la razón a altas presiones hasta provocar un colapso gravitatorio en el ser consciente. Este se agarra entonces al clavo ardiente de una razón silogística y argumentativa: arroja vanamente hielo escolástico en el incendio que del sujeto y de su pasión se propaga hacia la esposa asesinada y hacia el hogar.»

11 D. GutierRe. [Ap.] Pues médico me llamo de mi honra, yo cubriré con tierra mi deshonra.

D. JUAN. (MH, II, vv. 1031-1032)

$[\ldots]$

ya que ultrajes de mi honra quieren que pintor me vea, hasta que con sangre sea el pintor de mi deshonra. (PD, III, vv. 677-680)

Don Lope de Almeida es un soldado que no necesita construir un alter ego para llevar a cabo su secreta venganza, pero se compara con la serpiente, forma adoptada por el demonio en el paraíso:

D. LOPE.

([Ap.] Rigor, disimulemos, y dando rienda a toda la pasión, esperemos ocasión sufriendo y disimulando; y pues la serpiente halaga con pecho de ofensas lleno, yo, hasta verter mi veneno, es bien que lo mismo haga.) (SASV, III, vv. 445-453) 
Don Enrique por ser un personaje histórico, cuyo futuro anticipa veladamente Calderón. ${ }^{12}$

Y tampoco muere el Príncipe en El pintor de su deshonra, donde Calderón, dando otra vuelta de tuerca, reúne a dos pretendientes en torno a la desdichada Serafina, de la que aquel se enamora al instante -«que es necedad, que es locura / idolatrar hermosura / antes perdida que hallada» (I, vv. 880-882)- pese a estar cortejando a Porcia -hermana de Don Álvaro y confidente de Serafina. Aunque solo el espectador y el criado conocerán ese giro sentimental-«¿Qué importa, Celio, ver a Porcia bella / si de mi pena no es la causa ella?» (II, vv. 497-498)-, será precisamente este pretendiente inesperado que sorprende siempre a Serafina en momentos de turbación provocados por D. Álvaro el que, sin pretenderlo, hará realidad la

12 En 1369, en un combate cuerpo a cuerpo en los campos de Montiel, Don Enrique de Trastámara, hijo ilegítimo de Alfonso XI, acabó con la vida de su hermano, el rey Pedro I de Castilla -apodado "el Cruel» o "el Justiciero»- y reinó como Enrique II de Castilla. Calderón no puede evitar aludir al futuro de los dos hermanos en forma de presagio (III, vv. 243-246) y de aviso a través de una canción (III, vv. 482-485): "Para Consuegra camina [D. Enrique], / donde piensa que han de ser / teatros de mil tragedias / las montañas de Montiel» (III, vv. 586-589).

Siguiendo idéntico procedimiento, Calderón metaforiza la suerte del rey D. Sebastião, que en $A$ secreto agravio, secreta venganza se encuentra inmerso en los preparativos de la campaña de Alcazarquivir, donde desaparecería en 1578, dejando sin heredero el trono portugués, que en 1580 pasaría al pariente más cercano, Felipe II, iniciándose así el período de la «Monarquía Dual» (1580-1640):

REY [...]

Adiós, dulce patria mía,

que en él espero que vuelva

(puesto que es la causa suya),

donde ceñido me veas

de laurel entrar triunfante

de mil victorias sangrientas, dando a mi honor nueva fama, nuevos triunfos a la Iglesia, que espero ver...

([Voces] dentro.)

¡Fuego, fuego!

(SASV, III, vv. 870-878) 
tragedia que el rayo irá anunciando (I, vv. 1066-1070; III, vv. 230-236): para salvarla de un incendio, Don Juan entrega a Serafina desmayada a Don Álvaro, que huye con ella y se refugia en su casa de la montaña; allí se cita Porcia con el Príncipe, y allí vuelve este a encontrarla: «[Ap.] Que ya, viendo a Serafina, / espero vivir amando» (III, vv. 457458). Consciente de la dificultad del caso pero deseoso de poseer su hermosura - "y en tanto que amor percibe / modo en que pueda rendido / solicitar sus favores» (III, vv. 627-629)-, encarga a un pintor que, "a hurto» (III, v. 655), le haga un retrato, sin saber que se trata de Don Juan Roca, que va buscando a su esposa. Al sorprenderla con Don Álvaro, el marido ejecuta a tiros su venganza: «iMuere, traidor, y contigo / muera esa hermosura infame!» (III, vv. 985-986).

Así pues, pretendiente y marido se convierten sin sospecharlo en aliados para determinar la suerte de la dama, pues ambos propician su sacrificio. ${ }^{13}$ El primero empaña su imagen ${ }^{14}$ y pone en jaque su

13 "La víctima propiciatoria no es el Hombre-Dios sino la Mujer-Diosa, 'pequeño cielo' según la definición calderoniana. Doña Mencía, igual que Serafina y que Doña Leonor, son la hermosura, lo bello, eso que 'brujulea en el lejos de un imposible'. Esas tres mujeres bellas son tres mártires de la religión platónico-provenzal del amor, tres víctimas propiciatorias del amor-pasión. Deben ser inocentes para que su belleza mártir no sea mancillada ni empañada. Pero su ejecutor debe ignorar su inocencia con el fin de que su masacre pueda consumarse impunemente.» (TRÍAS, 1988, p.122-123)

14 Los maridos definen a la esposa -depositaria del honor conyugal-como el sol, cuyo magnífico resplandor, sin embargo, puede verse ensombrecido por una nube:

D. GUTIERRE. Y así acortemos discursos, pues todos juntos se cierran en que Mencía es quien es, y soy quien soy. No hay quien pueda borrar de tanto esplendor la hermosura y la pureza. Pero sí puede, mal digo; que al Sol una nube negra, si no le mancha, le turba, si no le eclipsa, le hiela. (MH, II, vv. 631-640)

D. LOPE. Leonor es quien es y yo soy quien soy, [y] nadie puede 
prestigio social; el segundo recoge las nefastas consecuencias de ese embate a la armonía conyugal, de ese cuestionamiento del orden establecido para restaurarlo, llegado el caso, al precio de una o dos vidas. A diferencia del pretendiente, los maridos no piden explicaciones y prefieren confirmar por sí mismos las sospechas que hacen peligrar la salud de su honor y que comienzan la noche en que sorprenden a un extraño en su casa y presienten que su mujer, cuando trata de justificar lo ocurrido, no les dice la verdad. La dama, que entre la ingenuidad y el orgullo ha decidido acrisolar amor y honor, ignora que su marido la vigila y la juzga mas, con todo, intuye que el cerco de lo fatal se va estrechando en torno a ella en cuanto escucha lo que este sería capaz de hacer si llegara a sentir celos:

D. GUTIERRE. [...]

¡Celoso! ¿Sabes tú lo que son celos?

Que yo no sé qué son, iviven los cielos!

Porque si lo supiera, y celos...

Dạ. MencíA. [Ap.] ¡Ay de mí!

D. GUTIERRE. Llegar pudiera

a tener... ¿qué son celos?

Átomos, ilusiones y desvelos,

no más que de una esclava, una criada,

por sombra imaginada,

borrar fama tan segura

ni opinión tan excelente.

Pero sí puede (iay de mí!)

que al sol claro y limpio siempre,

si una nube no le eclipsa,

por lo menos se le atreve,

si no le mancha, le turba,

$y$ al fin, al fin le oscurece.

(SASV, II, vv. 315-324) 
con hechos inhumanos

a pedazos sacara con mis manos

el corazón, y luego

envuelto en sangre, desatado en fuego,

el corazón comiera

a bocados, la sangre me bebiera,

el alma le sacara,

y el alma, ivive Dios!, despedazara,

si capaz de dolor el alma fuera.

Pero ¿cómo hablo yo desta manera?

Da. MEncíA. Temor al alma ofreces.

$(\mathrm{MH}, \mathrm{II}, \mathrm{vv} \text {. 999-1017) })^{15}$

Si Mencía siente escalofríos ante esa ingestión caníbal que Don Gutierre le describe, similares palabras dirige Don Lope, esta vez al pretendiente que, por el contrario, no capta el horror de esa posible vampirización con la que el marido simboliza su transformación si llegara a imaginar que su honor estuviera en peligro:

D. LOPE. [...]

Y si llegara a creer...

¿qué es creer?, si llegara

15 Más explícito aún será el repentino temor de Mencía al ver que su esposo lleva la daga que Don Enrique perdió en su casa la noche en que fue a visitarla:

Da. MencíA. iTente, señor!

¿Tú la daga para mí?

En mi vida te ofendí.

Detén la mano al rigor, detén...

D. GutierRE. ¿De qué estás turbada, mi bien, mi esposa, Mencía?

Da. Mencía. Al verte así, presumía que ya en mi sangre bañada, hoy moría desangrada.

(MH, II, vv. 361-369) 
a imaginar, a pensar

que alguien pudo poner mancha

en mi honor..., ¿qué es mi honor?,

en mi opinión y en mi fama,

y en la voz tan solamente

de una criada, una esclava,

no tuviera, ivive Dios!,

vida que no le quitara,

sangre que no le vertiera,

almas que no le sacara;

y éstas rompiera después,

a ser visibles las almas.

Venid, iréos alumbrando

hasta que salgáis.

D. LUIS. [Ap.] Helada

tengo la voz en el pecho.

¡Qué portuguesa arrogancia!

(SASV, II, vv. 856-873)

Don Luis trivializa esa velada amenaza atribuyéndola a la arrogancia propia de los portugueses, ${ }^{16}$ y del mismo modo resta importancia a otro aviso de Don Lope, que se ofrece a llevarlo en barca - Don Luis se ha citado con Leonor - no sin antes advertirle «que amistad de hombre agraviado / no es muy segura amistad» (SASV, III, vv. 484-485):

D. LOPE Pues conmigo iréis. (Ap. Llegó

la ocasión de mi venganza.)

D. LUIS $\quad[A p$. ¿ ¿Cuál hombre en el mundo alcanza

mayor ventura que yo?

16 Ver ÁLVAREZ SELLERS (2015). 
D. LoPE [Ap.] A mis manos ha venido,

y en ellas ha de morir.

D. LUIS ¡Que me viniera a servir

de tercero su marido!

[...]

D. LUIS $\quad[A p$.$] ¿Quién ha visto igual ventura?$

Él me lleva desta suerte

adonde a su honor me atrevo.

D. LOPE $\quad[A p$. $]$ Yo desta suerte le llevo

donde le daré la muerte. (Vanse los dos.)

(SASV, III, vv. 507-529)

Las tragedias de honra incorporan el elemento griego del fatum en forma de augurios, presagios o maldiciones, cuyo alcance no llegan a percibir los personajes, que recelan pero no retroceden. La primera Jornada concluye en las tres obras con la siniestra premonición de un porvenir cruento: la declaración de Don Álvaro a Serafina es interrumpida por un disparo, ${ }^{17}$ Don Luis promete amar a Leonor aunque le cueste la vida, lo mismo que Don Enrique justo antes de que Leonor, primera novia de Don Gutierre, profiera una sangrienta maldición:

SERAFINA. ¿'Yo ser tuya?

Un rayo... iVálgame el cielo!

17 Y no solo una vez:

D. Álvaro. Suspende el labio.

No prosigas; que primero

que yo viva sin ti, un rayo

me mate... (Disparan [dentro un arcabuz].)

¡Válgame el cielo!

SERAFINA. ¡Ay de mí, que ya este acaso,

segunda vez sucedido,

mi muerte está pronunciando.

(PD, III, vv. 230-236) 


\section{(Disparan dentro.)}

D. Álvaro. iAy de mí! iCuánto me asusta que el aire pronuncie el trueno, cuando tú el rayo pronuncias! (PD, l, vv. 1066-1070)

D. LUIS. [...]

Siga mi suerte atrevida su fin contra tanto honor, porque he de amar a Leonor, aunque me cueste la vida. (SASV, I, vv. 829-832)

D. EnRIQUE. ([Ap.] Con ocasión de la caza, preso Gutierre, podré ver esta tarde a Mencía.) Don Diego, conmigo ven; que tengo de porfiar hasta morir, o vencer. (Vanse.)

Dạ. LEONOR. iMuerta quedo! iPlegue a Dios, ingrato, aleve y cruel, falso, engañador, fingido, $\sin \mathrm{fe}, \sin$ Dios y $\sin$ ley, que como inocente pierdo mi honor, venganza me dé el cielo! iEl mismo dolor sientas, que siento, y a ver llegues, bañado en tu sangre, deshonras tuyas, porqué mueras con las mismas armas 
que matas, amén, amén!

¡Ay de mí!, mi honor perdí.

¡Ay de mí!, mi muerte hallé.

(MH, I, vv. 1001-1020)

Y si el pretendiente llega por sorpresa y su intento de transgresión del orden social desemboca en tragedia, hay otro personaje que encarna también la figura del antagonista cuya actuación sigue parámetros inversos pero resulta mucho más efectiva: se trata de la que podríamos llamar "dama al acecho», esas damas que fueron desbancadas por la esposa en el corazón del protagonista pero que, como el pretendiente recién llegado, creen seguir teniendo derechos sentimentales sobre aquel con quien aspiraban a casarse. La gran diferencia entre ambos tipos de antagonista es que ellas nunca se han marchado, permanecen expectantes mientras se desarrolla la disputa pasional entre los cónyuges y el pretendiente y saben esperar su oportunidad y actuar en el momento justo para conseguir su objetivo: recuperar a su antiguo enamorado una vez que él mismo ha despejado el camino del obstáculo que lo impedía, la dama que eligió por esposa.

El médico de su honra es la única de las tres obras calderonianas en la que aparecen a la vez ambos personajes, pues si Mencía tiene un pasado sentimental en el que, contra lo que supondrá su marido, rechazó a Don Enrique porque su condición de príncipe le impedía casarse con ella, también Don Gutierre ha participado en lides amorosas. Antes de casarse, tuvo una relación con Doña Leonor, a la que dejó porque una noche vio saltar un hombre desde el balcón de la dama. Puesto que aún eran solteros, Don Gutierre se limita a deshacer el compromiso y se casa con otra, 
pero Leonor llegará hasta el Rey para abogar por su inocencia y pedirle reparación, a lo que el soberano responde que nada puede hacer porque Don Gutierre ya se ha desposado, "pero yo haré / justicia como convenga» ( $M H$, I, vv. 680-681) e insiste en "oír a la otra parte / disculpas suyas» (I, vv. 685-686). Al escuchar escondida la razón del abandono, Leonor pronuncia esa terrible maldición dirigida a Don Gutierre pero que inevitablemente salpica a Mencía, personaje al margen de lo sucedido entre ambos y doblemente inocente, pues ni acepta a Don Enrique ni interfiere en el romance de Leonor, pero que pagará la imprudencia del primero y el afán de venganza de la segunda.

Pese a creer Leonor legítimas sus aspiraciones, Don Gutierre ha dado por concluido ese capítulo de su vida porque ya no puede confiar en ella, y subraya su carácter secundario comparando a su esposa con el sol y a las otras damas con la luna (I, vv. 520-524), cuya luz nunca puede igualarse a la del astro rey, «porque hasta que sale el Sol, / parece hermosa una estrella» (I, vv. 543-544). Don Gutierre ha pasado página y, sin mirar atrás, se confiesa un esposo enamorado. En los raptos de pasión, la mujer es vista como un ser superior cuya perfección, en la línea de la donna angelicata, solo puede proceder de la divinidad, y pretendiente y marido destacan su naturaleza sublime: "Es su hermosura divina» (refiriéndose a Serafina, $P D$, p.124, 131, 151) -«jO hermosura celestial!» (Federico a Casandra en El castigo sin venganza, p.316)-, "cielo, gloria mía» (Gutierre a Mencía, MH, p.86), «divina Leonor» (SASV, p.26), pero también su condición de poseedores de esa hermosura: «Mi bien, mi dueño, mi esposa» (PD, p.142-143; 162, 165, 186), «mi bien, mi esposa» (SASV, p.89; 40, 87), «mi bien, mi esposa, Mencía» (MH, 
p.65; 86), de la que, en consecuencia, pueden disponer. Porque aunque la supuesta falta de Mencía sea comparable a la de Leonor, un abismo separa ambas actuaciones: el matrimonio, que obligará a Don Gutierre a tomar medidas drásticas para recuperar el honor que cree perdido. Y si para Leonor el abandono supuso la muerte social, para Mencía, que tiene vedada la ruptura, el vínculo conyugal implicará la muerte física.

Pero Mencía no perece de cualquier manera, sino tal y como dispuso Leonor, «bañada en sangre». Cuando Don Gutierre considera haber reunido las pruebas suficientes para juzgarla culpable de adulterio, la deja encerrada en casa con una terrible carta que le anticipa su ejecución; ${ }^{18}$ entonces llama al barbero para que le efectúe una sangría porque está «enferma», ${ }^{19}$ pero incluso este personaje sospecha de las aviesas intenciones de quien reclama sus servicios y deja impresa una mano ensangrentada en la puerta de Don Gutierre para poder identificar la casa cuando le cuente al Rey lo sucedido. Denuncia que este escucha además por boca de los criados, que también presienten la triste suerte de su señora. El Rey llega tarde, pues Mencía ha muerto desangrada: «Ya se ve cuán fácilmente/ una venda se desata» (MH, III, vv. 810-811) 18 Dạ. Mencía. [...]

\section{De mi esposo es la letra, y desta suerte \\ la sentencia me intima de mi muerte: \\ [Lee.] «El amor te adora, el honor te aborrece; \\ y así el uno te mata y el otro te \\ avisa. Dos horas tienes de vida: cristiana \\ eres, salva el alma, que la vida es imposible.»}

(MH, III, vv. 446-447, p.103)

19 D. GUTIERRE. [...]

Médico soy de mi honor,

la vida pretendo darle

con una sangría; que todos

curan a costa de sangre.

(MH, III, vv. 582-585) 
dice Don Gutierre para encubrir el crimen justificándolo como una muerte accidental (III, vv. 773-823). Pero el final es tan inesperado como desalentador. Justo en ese momento Leonor pasaba por allí, y el Rey, que le prometió justicia, le concede su mano a Don Gutierre para reparar la ofensa que aquel le hizo al dejarla. Leonor acepta gustosa, satisfecha de haber conseguido su propósito aun a costa de la vida de Mencía y tras escuchar la terrible advertencia de Don Gutierre, que le revela que ya ha sido médico de su honra una vez y que puede volver a serlo. La respuesta de Leonor es aún más escalofriante:

D. GutierRE. Los que de un oficio tratan, ponen, señor, a las puertas un escudo de sus armas; trato en honor, y así pongo mi mano en sangre bañada a la puerta; que el honor con sangre, señor, se lava.

REY. Dádsela, pues, a Leonor; que yo sé que su alabanza la merece.

D. GUTIERRE. Sí la doy. [Dale la mano.]

Mas mira que va bañada en sangre, Leonor.

Dạ. LEONOR. No importa;

que no me admira ni espanta.

D. GutierRe. Mira que médico he sido de mi honra: no está olvidada la ciencia. 
Da. LEONOR. Cura con ella mi vida, en estando mala.

D. GutierRe. Pues con esa condición te la doy. (MH, III, vv. 885-903)

Lejos de temer por su vida pese al ejemplo recibido, Leonor autoriza a Don Gutierre a curarla si cae, como Mencía, «enferma», olvidando que ella ya lo estuvo en el pasado y que su soltería la libró de correr semejante suerte. Pero en las tragedias de honra el conflicto entre amor / honor, pasado / presente, se enmarca en un trasfondo decisivo, aquel que enfrenta al individuo con la sociedad, al imperativo moral con el colectivo. Para los defensores del sistema la honra, el ser social, es más importante incluso que la vida. El conato de rebeldía de pretendiente y esposa acaba fatalmente, pero el futuro matrimonio entre Don Gutierre y Leonor asegura la restauración de un orden que no permite fisuras pasionales, sostenido por conciencias alucinadas instaladas en una realidad ficticia, creyéndose médico y paciente, pero, al fin, eliminados aquellos que hicieron tambalear el edificio del honor, satisfactoria, pues «Cuerdamente / sus agravios satisfizo» (III, vv. 744-745) dirá el Rey resumiendo la actuación como médico de su honra de Don Gutierre.

Otra «dama al acecho» es Aurora en El castigo sin venganza (1631) de Lope de Vega, aunque el conflicto se desarrolla desde coordenadas diferentes. El Duque de Ferrara, amigo de galanteos, se ha casado por poderes con la joven Casandra forzado por sus vasallos (I, vv. 665-671) para que esta le dé un heredero legítimo. ${ }^{20}$

20 También Don Juan Roca, que ha dejado "pasar la primera / edad de mi primavera» $(P D, \mathrm{I}, \mathrm{vv} .26-27)$ se casa "ya rendido a la atención / de mis deudos, o a que fuera / lástima que se perdiera, / faltándome sucesión, / un mayorazgo que creo / que es ilustre y principal / y no de poco caudal» (I, vv. 57-63). 
Pero envía a su hijo Federico a buscarla, y la atracción surge de forma tan espontánea como inmediata. El Duque, además, se limita a consumar el matrimonio (II, vv. 1034-1037) y pierde el interés por su esposa que, sintiéndose despreciada, decide entregarse a Federico tras arrancarle una confesión amorosa. En ausencia del Duque la relación prospera pero, a su regreso, una carta anónima le revela lo sucedido. Entonces tiende una trampa a Federico para que mate a Casandra creyendo que se trata de un enemigo de su padre y luego manda que lo maten por haber asesinado a su madrastra, quedando finalmente solo, pues hasta el gracioso decide abandonar la Corte horrorizado por los acontecimientos.

Como Leonor en A secreto agravio, secreta venganza, Casandra encuentra antes al pretendiente que al esposo, pero aquel no pertenece a su pasado, por lo que ambos candidatos comparten no solo el espacio sino también el tiempo. La simpatía instantánea que siente por Federico le impedirá reparar en su prima Aurora, que antes de conocerla da por hecho que se casará con él, tal y como corresponde a su posición social:

AURORA. [...]

Una ley, un amor, un albedrío,

una fe nos gobierna,

que con el matrimonio será eterna, siendo yo suya, y Federico mío;

que aun apenas la muerte

osará dividir lazo tan fuerte.

[...]

no hay en Italia agora casamiento

más igual a sus prendas y a su estado 
que yo;

[...]

Si le casas conmigo, estás seguro

de que no se entristezca

de que Casandra sucesión te ofrezca,

sirviendo yo de su defensa y muro.

(I, vv. 718-733)

Adoptando un rol masculino, Aurora pide al Duque la mano de Federico ofreciéndose como la mejor opción en cuestión de rango, planteando así el matrimonio como un contrato con indudables ventajas sociales pero sin aludir a cuestiones sentimentales.

La comitiva llega por fin a Ferrara, donde Casandra es recibida por el Duque, del que se confiesa esclava — «Para ser de vuestra Alteza / esclava, gran señor, vengo» (I, vv. 828-829), como también dirán Mencía y Serafina - y por Aurora, de la que espera «ver, Aurora, que os tengo / por amiga y por señora» (I, vv. 847-848). Ambos ponderan, a su vez, el aumento que supone la llegada de Casandra (I, vv. 821-827; I, vv. 849-854), que se augura un futuro prometedor:

CASANDRA. Con tales favores entro que ya en todas mis acciones próspero fin me prometo.

(l, vv. 855-857)

Federico vive atormentado por su pasión secreta hacia su madrastra (II, vv. 1232-1243), ,11 cuyo carácter incestuoso subraya 21 Batín. Pues mira como lo acierto: que te agrada tu madrastra y estás entre ti diciendo...

Federico. No lo digas; es verdad, pero yo, ¿qué culpa tengo, pues el pensamiento es libre? (I, vv. 977-982) 
Lope (I, vv. 495-497; vv. 510-521; vv. 775-781), y se resiste a aceptar la propuesta de matrimonio con Aurora que el Duque le transmite por la misma razón que Don Gutierre abandonó a Leonor, es decir, porque cree que ella está siendo cortejada por otro, el Marqués Gonzaga - miembro del séquito de Casandra - y ello «es escribir sobre papel borrado» (II, v. 1170); el Duque, experto en lides amorosas, contrarresta esta imagen con la del cristal, que de mirarlo se empaña, pero «luego que se limpia y se reporta, / tan claro queda como estaba de antes» (II, vv. 1177-1178), insinuando que la opinión no debe ser más apreciada que la conveniencia -sin embargo, cuando se sepa afrentado, no dudará en aplicar el código del honor con todo su rigor. Pero su hijo vislumbra ese matrimonio como una fragua en que el fuego del marido no haría sino avivar las Ilamas de la pasión por el amante (II, vv. 1180-1191), por lo que no quiere dar «fuego a mi honor y humo a mi fama» (II, v. 1191) emulando el conflicto conyugal de las tres tragedias calderonianas; Federico sabe aprovechar la ventaja de que dispone, esto es, su conocimiento de la existencia del pretendiente.

$Y$ es que en la segunda Jornada el comportamiento de los varones parece haber cambiado, lo cual deja perplejas a las damas. Casandra se lamenta del abandono del Duque: «Pero que con tal desprecio / trate a una mujer de precio, / de que es casado olvidado» (II, vv. 1049-1051) y Aurora, fiel a la amistad que predijo la duquesa, le confiesa que Federico la ignora y no sabe la causa (II, vv. 1250-1251), "que antes de su casamiento / la misma luz de sus ojos / era yo, pero ya soy / quien en los ojos le doy, / y mis ojos sus enojos» (II, vv. 1259-1263). Casandra promete hablar con él para averiguarlo: «¿Sabes ya lo que te quiero?» (II, v. 1306) comienza 
diciendo tras abrazar a un tembloroso hijastro que se siente morir - "Yo me muero sin remedio, / mi vida se va acabando» (II, vv. 14161417) - no por miedo a perder su herencia sino a declararse a una mujer que no es Aurora. Casandra intuye que es ella el objeto de esa pasión prohibida, y esa sospecha, unida al desdén del duque - «porque con marido bueno, / ¿cuándo se vio mujer mala?» (II, vv. 1062-1063)-22 la deciden a forzar la confesión de Federico (II, vv. 1872-1920) y a embarcarse en una relación prohibida que solo será posible mientras permanezca en secreto, pues las leyes humanas son más severas que las divinas, como ella bien sabe: «que diferencian intentos / el ver Dios los pensamientos / y no los ver el honor» (II, vv. 1552-1591).

Ajena al resultado de las conversaciones entre hijastro y madrastra, Aurora intenta atraer la atención de Federico dándole celos con el Marqués Gonzaga, estrategia absolutamente errada, pues la reacción del varón soltero ante esa tesitura es abandonar a la dama, como hace Don Gutierre pese a haber establecido una relación con Leonor y, en el caso de Federico, la actuación de su prima solo contribuye a darle un pretexto para alejarse aún más de ella (II, vv. 1765-1773). Sin embargo, hay un vínculo que los une: los tres se sienten personajes sin alma. Asumiendo esa pasión transgresora, Federico es «cuerpo sin alma» (II, v. 2002) y Casandra

\section{CASANDRA. [...]}

$$
\begin{aligned}
& \text { Cuando a imaginar me inclino } \\
& \text { que soy lo que quiere el conde, } \\
& \text { el mismo engaño responde } \\
& \text { que lo imposible imagino; } \\
& \text { luego mi fatal destino } \\
& \text { me ofrece mi casamiento, } \\
& \text { y en lo que siento consiento; } \\
& \text { (II, vv. 1552-1558) }
\end{aligned}
$$


anuncia que «Alma y sentidos perdí» (II, v. 2022). Ambos se definen como fantasmas de sí mismos e identifican amor y muerte:

CASANDRA. Yo voy muriendo por ti.

FEDERICO. Yo no, porque ya voy muerto.

CASANDRA. Conde, tú serás mi muerte.

FEDERICo. Y yo, aunque muerto, estoy tal

que me alegro, con perderte,

que sea el alma inmortal, por no dejar de quererte.

(II, vv. 2024-2030)

Y «sin alma» (III, v. 2078) queda Aurora cuando sorprende el reflejo de un beso en un espejo - ella misma fue comparada con el cristal por el duque - y comprende la traición de Casandra y Federico, "tan ciegos / que parece que compiten / en el amor y el desprecio» (III, vv. 2081-2083). Se lo cuenta al Marqués Gonzaga, que formula la única solución a los conflictos de honra: «¿Cómo quieres que se limpie / tan fea mancha sin sangre, / para que jamás se olvide» (III, vv. 2128-2130). Razón tenía Casandra al temer más al honor que a Dios. Tras cuatro meses de ausencia, el Duque regresa dispuesto a dedicarse a su familia (III, vv. 2357-2363), y es entonces cuando Federico abre los ojos - «Basta el tiempo que tan ciegos / el amor nos ha tenido» (III, vv. 2728-2729) - y plantea dos soluciones para restaurar el orden dislocado: la muerte (III, vv. 2257-2265) o casarse con Aurora, lo cual rechaza Casandra rotundamente: "Quíteme el duque mil vidas, / pero no te has de casar» (III, vv. 2287-2288). Sin embargo, Federico se decide por la segunda opción y pide la mano de Aurora al Duque, al que un papel anónimo ha revelado con suma claridad la infamia - «'Señor, mirad por vuestra 
casa atento; / que el conde y la duquesa en vuestra ausencia...' [...] 'ofenden con infame atrevimiento / vuestra cama y honor'» (III, vv. 2484-2490). El Duque le responde que debe consultar también a su madre, Casandra, a lo que Federico alega que su madre ha muerto hace años. Si cuando la vio sentía que ella le había infundido el alma, «que para nacer con alma / hoy quiero nacer de vos [...] vos me habéis hecho de nuevo, / que yo sin alma vivía» (I, vv. 510517), ahora que la ha perdido trata de recuperarla mediante ese matrimonio de conveniencia enunciado por Aurora. Sin embargo, esta lo rechaza esgrimiendo una razón contraria a la que había dado cuando pidió al Duque su mano: «El casarse ha de ser gusto» (III, v. 2687), y es precisamente el personaje que ha experimentado la verdad de esa sentencia quien la corrobora: "no uséis del poder; que amor / es gusto, y no ha de forzarse» (III, vv. 2694-2695) dice Casandra. El final es el esperado: el Duque urde un castigo que no parezca una venganza para no pregonar la ofensa (III, vv. 2850-2853) - como hace Don Lope en A secreto agravio, secreta venganza o Don Gutierre en El médico de su honra - y, tras la muerte de Federico y Casandra, Aurora se marcha a Mantua, donde se casará con su pretendiente, el Marqués Gonzaga.

A diferencia de Leonor en El médico de su honra, Aurora rechaza lo que anhelaba, la boda con su primo, porque ella no ha sufrido la deshonra pública del abandono y, por lo tanto, puede elegir a otro hombre. La ruptura del compromiso entre Don Gutierre y Leonor no limitaba las opciones del varón pero, en cambio, suponía la muerte social de la dama, que solo podía restaurar su honor entrando en un convento ( $M H, I$, vv. 671-672) o casándose con su ofensor, por eso rechaza la propuesta matrimonial de Don Arias, que se ofrece a 
reparar el agravio por haber sido quien saltó desde el balcón: «que pues fui / causa de penas tan tristes, / si esposo por mí perdistes, / tengáis esposo por mí» (II, vv. 737-740).

Mas aunque su elección final sea diferente, sus trayectorias convergen: ambas satisfacen su deseo y salen airosas del infortunio que envuelve a cuantos las rodean, pero ambas son responsables del mismo. Aunque la tragedia áurea supera planteamientos maniqueístas y convierte el fatum, el hado, en elemento estético que anticipa en forma de augurio la suerte de los personajes, son sus propios errores los que los conducen a un desenlace fatal, ${ }^{23}$ pues en el contexto del Barroco español se descarta el influjo de los astros, de un destino ciego o de la divinidad como justificación de las malas actuaciones, por lo que el personaje queda a merced de su conciencia y de los imperativos morales y sociales que deben guiarlo. Pero tanto Leonor como Aurora contribuyen a inclinar la balanza del lado de lo siniestro: Leonor desea a Don Gutierre que vea bañada en sangre su deshonra y todo apunta a que Aurora sea la autora del papel delator, pues es quien descubre la infamia y escucha del Marqués Gonzaga el consejo de una venganza sangrienta. Ninguna tiene las manos limpias, pero ninguna se arrepiente ni lamenta la triste suerte de su rival, pues en cuestiones de honra y apariencia da igual ser inocente como Mencía o culpable como Casandra.

También, contra todo pronóstico, se sale con la suya Nise en La fuerza de la ley (ca. 1644) de Agustín Moreto, tragedia atípica

23 «Los dramaturgos españoles no presentan sobre la escena víctimas del destino o de la mala fortuna, sino solamente del mal proceder propio o ajeno. El principio de la justicia poética requería no solamente que el culpable sufriese sino también que no hubiera víctimas inocentes; aun cuando el personaje trágico sea víctima de un mal que otro le causa, casi invariablemente ha contribuido a él por su propia culpa.» (PARKER, 1976, I, p.337-338) Ver ÁLVAREZ SELLERS (En prensa). 
en la que el autor parece más empeñado en deconstruir el género que en sostenerlo, relativizando mediante el propio argumento y las excesivas incursiones cómicas las situaciones características de la tragedia de honra. ${ }^{24}$ En este caso, una decisión arbitraria del poderoso que desbarata dos parejas pone en marcha el mecanismo trágico: el rey Seleuco tiene dos hijos, Demetrio y Nise, enamorados, respectivamente, de Aurora y Alejandro, que les corresponden. Sin embargo, para evitar el matrimonio de sus hijos con alguien de rango inferior, decide casar al valiente Alejandro con Aurora, haciendo a todos infelices, ${ }^{25}$ aunque luego considerarán solución más práctica la desdicha que la muerte: ${ }^{26}$

NISE. ¿Y será alivio tu muerte?

ALEJANDRO. Para mi mal será alivio.

NISE. ¿Y para mí qué será?

AlEJANDRo. Para ti no sé, imagino que es menor mal verme ajeno.

NISE. $\quad$ No, Alejandro, no lo admito.

Mi padre es muy riguroso, pues mi desdicha lo quiso; dale ya la mano a Aurora

24 Ver ÁLVAREZ SELLERS (2014).

25 Así responde a Alejandro cuando este le pide la mano de Nise: «¿Mi hija a vos? ¿Estáis sin juicio?» (I, v. 863), animándolo a desterrar sus «esperanzas locas» y advirtiéndole que si esa misma noche no se casa con Aurora «para inobedientes bríos / tienen cuellos las cabezas / y mis decretos, cuchillo» (I, vv. 879-881). Agustín MORETO, La fuerza de la ley (2008).

26 Y Demetrio advierte a su padre que si lo mata se quedará sin heredero:

DEMETRIO. [...]

Si esa corona aficiona por dármela vuestra alteza, y mi vida no perdona, ¿de qué sirve la corona si me quita la cabeza?

(I, vv. 707-711) 
y vivas felices siglos.

ALEJANDRO. ¿A ese rigor me aconsejas?

(I, vv. 964-974)

Como Casandra en El castigo sin venganza, Aurora se queja de "estar mal casada» (II, v. 1037) por la falta de interés de su marido tras consumar el matrimonio. Recibe también la visita clandestina de Demetrio, al que se resiste a duras penas - ([Ap] Mi pecho no es poderoso... / Cielos, al honor apelo...)» (II, vv. 1174-1175)-, ${ }^{27}$ el cual olvida en la casa unos guantes perfumados cuando está a punto de ser sorprendido por Alejandro, que ha tropezado con su propia sombra y se ha torcido un pie. Ese objeto afeminado - «Un guante que huele bien / obliga a discurrir mal» (II, vv. 1304-1305), pues «el olor, sabe el discreto, / que es símbolo del honor» (II, vv. 1520-1521)contrasta con la daga que pierde Don Enrique en casa de Mencía y ante la que ella retrocederá espantada al verla luego en poder de su esposo. A diferencia también de Don Gutierre con Leonor, Alejandro no ha olvidado a su primera dama y, si hace un instante desconfiaba de su esposa, vacilando entre el amor y los celos, le pide ahora a Nise que le dé alivio. Demetrio pretende lo mismo y planea regresar a casa de Aurora upara lograr atrevido / - a costa de todo riesgo- / de tanto ardor el alivio» (II, vv. 1476-1478). Sucede entonces una escena de máxima confusión, a oscuras, en el aposento de la dama, y hasta el propio Rey acude -avisado por Nise, que no ha logrado hacer desistir 27 AURoRA. (Ap. Responde, honor: ¿qué he de hacer?

¡Dura ley, fiero pesar!

Si obligas a despreciar, ¿para qué dejas querer?)

Señor, ya trocada estoy desde que llegué a casarme:

la desdicha fue trocarme, mas ya trocada, otra soy.

(I, vv. 1126-1133) 
a su hermano del empeño- y deshace el entuerto con una mentira (II, vv. 1824-1830), lo cual aumenta las sospechas de Alejandro, que se siente como Don Gutierre:

AlEJANDRO. ([Ap] Honor, ya es cierta la herida, lo que ahora importa es curalla.) (II, vv. 1852-1853)

La inconveniente decisión de Seleuco ha convertido además a Nise y Aurora en rivales, y ninguna comprende el dolor de la otra, tal y como se dicen veladamente utilizando una canción como excusa: "Que mueras o vivas triste, / ¿qué culpa te tengo yo?». Si los celos son peligrosos consejeros, ambos hermanos reconocen sentirlos, al tiempo que Alejandro sigue encaprichado de Nise:

ALEJANDRo. Porque hoy le asista en el campo

me llama el Rey. ¿Dónde va

mi obediencia, si de Nise

vengo al peligro mortal?

(III, vv. 2174-2177)

Aunque, al ver a Demetrio dormido con un retrato de Aurora en la mano, recuerda sus deberes conyugales y lo acusa de ser lo que imaginó Don Juan Roca: «De mi deshonra pintor / has sido;» (III, vv. 2246-2247) pero, como le sucede a Don Gutierre, no puede matarlo porque es el príncipe. Al sorprender una segunda visita nocturna del pretendiente propiciada por la criada, Alejandro despeja sus dudas $y$, como otros maridos que se creen afrentados, mata a su mujer fuera de escena, pero después no trata de disfrazar el crimen o la venganza de accidente, sino que pide a Demetrio que lo mate y le echa la culpa del desenlace (III, vv. 2798-2805). La oportuna llegada de Seleuco y Nise lo evita, pero a cambio el Rey pretende 
aplicar a su hijo el duro castigo que dicta la ley: sacarle los ojos. Pero Nise, siempre práctica y pertinente, le recuerda que es el heredero - ¿Cómo ha de quedar sin ojos?» (III, v. 2844)- y entonces el Rey decide sacarle uno y otro a sí mismo para que sus vasallos tiemblen ante la fuerza de la ley, y finalmente autoriza la boda de Nise con Alejandro, de cuya difunta esposa ya nadie se acuerda. De hecho, la dama expresa su contento con una demoledora sentencia:

NISE. jDichoso el mal que tal bien

ha causado!

(III, vv. 2911-2912)

Lo mismo dice Don Álvaro cuando, dispuesto a recuperar el amor pasado a toda costa y con la ayuda del azar, secuestra a Serafina: «Diga la fama / que siempre la propia dicha / está en la ajena desgracia» (PD, II, vv. 963-965). Y, en efecto, este parece ser el lema de los pretendientes y las damas al acecho, antagonistas ambos de los protagonistas y responsables, directa o indirectamente, de la quiebra de la armonía conyugal. En contextos similares, ambos actúan como agentes transgresores que desestabilizan el orden que fue establecido no solo contra su voluntad, sino también contra la de la esposa, que será quien sufra las consecuencias fatales del choque de egocentrismos de cuantos la rodean y de su propia imprudencia al hacerles frente.

Pero aunque cumplan idéntica función, su despliegue actancial difiere sustancialmente; el pretendiente inicia el conflicto, mientras que la dama encuentra los hechos consumados y se convierte en secundaria sin pretenderlo: Leonor es abandonada por Don Gutierre antes de casarse, Aurora despreciada por Federico sin razón aparente, y Nise -que no puede casarse hasta que lo haga 
su hermano (I, vv. 361-376) - relegada por una mala decisión de su padre. Si en la comedia es la mujer quien se hace con las riendas de la acción, en la tragedia no puede mover ficha hasta que no lo hace el varón, tomando entonces decisiones apresuradas e inconvenientes como reacción a las muestras de amor y honor, respectivamente, de pretendiente y marido en el caso de la esposa, o aguardando tiempos mejores cuando se trata de la dama al acecho, que sabrá esperar su oportunidad y actuar en el momento justo, saboreando una victoria que escapa al pretendiente, el cual, si no es de sangre real, correrá la misma suerte que su amada.

Aunque, como hemos visto, las coordenadas dramáticas puedan variar, e incluso en una obra tan contradictoria o singular como La fuerza de la ley - única incursión de Moreto en el género trágico pero que roza la parodia del mismo -, la lección final de todas las tragedias de honra coincide: es posible atentar contra el sistema y procurar inclinar las circunstancias hacia el gusto, pero el orden siempre recuperará su forma; el pretendiente puede llegar a secuestrar a Serafina para recobrar un pasado que se niega a reconocer como irremisiblemente perdido, o incluso puede llegar a vencer la resistencia inicial de esposas como Leonor o Aurora pero, al contrario que la dama al acecho, nunca alcanzará su objetivo, porque su propuesta transgresora es opuesta a la de ella, que aspira a reincorporarse en el sistema social mediante el matrimonio, principio sagrado y escollo insalvable que el pretendiente se empeña en destruir. Tras castigar con la muerte a su mujer $y$, si puede ser, también al pretendiente, el marido obtiene el beneplácito del Rey aun conociendo este la terrible justicia aplicada y, es más, el permiso para volver a casarse llegado el caso, reparando así el honor de 
la dama agraviada, como Leonor, o sellando la realización de sus deseos aunque estos hayan pasado por encima del mal ajeno, como declara una triunfante Nise.

Como decíamos al principio, en la tragedia española del Siglo de Oro el enfrentamiento entre el individuo y el imperativo social desemboca en un conflicto trágico porque todos, oponentes o defensores del sistema, deben renunciar al sentimiento y despejar de escrúpulos el camino, como hacen el marido y la dama al acecho, para permanecer en una sociedad que no admite fisuras pasionales y que devora a quienes las provocan o admiten, como sucede con el pretendiente y la esposa. Lanzar una piedra al vacío solo alterará momentáneamente la superficie del agua pero, cuando esta se hunda en el fondo, las ondas desaparecerán y todo volverá a quedar como si ese impacto no se hubiera producido, como si el pretendiente no hubiera aparecido, como si la esposa no hubiera existido...

\section{REFERENCIAS}

ÁLVAREZ SELLERS, María Rosa (1997). Análisis y evolución de la tragedia española en el Siglo de Oro: la tragedia amorosa. Kassel, Reichenberger, 1997, Colección «Teatro del Siglo de Oro. Estudios de Literatura», no 33, 34 y 35 (tres volúmenes).

. (2012). «'Lo trágico y lo cómico mezclado': Lope de Vega y la creación de la tragedia 'al estilo español'». In: BRIOSO SANTOS, Héctor y CHERECHES Alexandra (Coords.). "Callando pasan los ligeros años...»: el Lope de Vega joven y el teatro antes de 1609, Papeles de Teatro 1. Madrid: Liceus. pp.45-68.

------. (2013). «¿'Los casos de honra son mejores'? Moreto o la deconstrucción de la tragedia». Agustín de Moreto y Cavana (1618-69): Theater and Identity. Revista eHumanista, Journal of Iberian Studies, pp.21-60.

(2015) «Reyes, santos y maridos: personajes portugueses en el teatro español del Siglo de Oro». Hipogrifo. Revista de literatura y cultura del Siglo de 
Oro, vol. 3, núm. 2, noviembre, pp.15-31.

. (En prensa). "'Y porque veas aquí / cómo mienten las estrellas': los misterios del hado en la tragedia del Siglo de Oro», Esoterismo y brujería en la literatura del Siglo de Oro. Burgos: Universidad de Burgos.

CALDERÓN DE LA BARCA, Pedro (1967). A secreto agravio, secreta venganza. Ed. Ángel Valbuena Briones, Madrid: Espasa-Calpe.

------. (1970). El médico de su honra. El pintor de su deshonra. Ed. Ángel Valbuena Briones. Madrid: Espasa-Calpe.

MORETO, Agustín (2008). La fuerza de la ley. Ed. Esther Borrego Gutiérrrez. Kassel: Reichenberger.

PARKER, Alexander A. (1976). «Aproximación al drama español del Siglo de Oro». In: DURÁN, Manuel y GONZÁLEZ ECHEVARRÍA, Roberto. Calderón y la crítica: historia y antología. Madrid: Gredos, vol. I.

RODRÍGUEZ ADRADOS, Francisco (1972). Fiesta, comedia y tragedia. Barcelona: Planeta.

RUIZ RAMÓN, Francisco (1984). Calderón y la tragedia. Madrid: Alhambra. TRÍAS, Eugenio (1988). La aventura filosófica. Madrid: Mondadori.

VEGA, Lope de (1989). El castigo sin venganza. Ed. A. David Kossoff. Madrid: Castalia. 